\title{
Frequency and Distribution of Dental Anomalies in Iran: A Radiographic Survey
}

\author{
Maryam Tofangchiha, Somayyeh Azimi, Masoud Neirizi
}

\begin{abstract}
Aim: Many epidemiological studies have been performed around the world in order to determine the frequency of different types of dental anomalies. There are regional and ethnic variations in the prevalence of dental anomalies.

To determine the prevalence of developmental and acquired dental anomalies in Iran, study was done from 2011 to 2012.
\end{abstract}

Materials and methods: A total of 1,000 digital panoramic radiographs of patient were evaluated which consisted of 424 (42/4\%) male and $576(57 / 6 \%)$ female. Data were analyzed by Chi-square and Fisher exact tests.

Results: Wisdom tooth impaction was the most prevalent anomaly $(41.4 \%$ in females and $36 \%$ in males) followed by missing $(8.7 \%$ male, $7 / 3 \%$ female), microdontia $(3.2 \%)$, dilacerations $(2.2 \%)$, macrodontia $(1 \%)$, supernumerary teeth $(0.8 \%)$, fusion and taurodontism $(0.2 \%)$. A case of bilateral second mandibular molar impaction was observed. Germination, transposition and concrescence were not observed. Among the acquired anomalies, hypercementosis $(0.6 \%)$ and internal resorption $(0.4 \%)$ were the most prevalent respectively. External resorption was not observed.

Conclusion: Comparison of these results with those of other studies, showed that the frequency of these disorders were different in countries and communities around the world. Knowledge about these anomalies may facilitate the endodontic, prosthodontics, periodontics and surgical management of such teeth.

Keywords: Dental anomalies, Panoramic, Prevalence.

How to cite this article: Tofangchiha M, Azimi S, Neirizi M. Frequency and Distribution of Dental Anomalies in Iran: $A$ Radiographic Survey. Int J Experiment Dent Sci 2013;2(1): 14-17.

\section{Source of support: $\mathrm{Nil}$}

Conflict of interest: None declared

\section{INTRODUCTION}

Dental anomalies may include variations in the number, size, morphology, or eruptive pattern of the teeth. ${ }^{1}$ There are a wide range of these anomalies among different populations of the world. These anomalies may be congenital or acquired due to genetic or environmental factors. ${ }^{2}$ Congenital abnormalities are typically genetically inherited anomalies and developmental anomalies occur during the formation of teeth. In contrast, acquired abnormal ities result from changes to teeth after normal formation. ${ }^{1}$ In other aspect, abnormalities of teeth may be part of systemic or syndromes disorders. ${ }^{2}$

Panoramic radiography is used for diagnostic goals such as third molar location, intraosseous lesions and developmental anomalies. ${ }^{3}$ It seems that digital radiography is more accurate for these diagnostic approaches. ${ }^{4}$ This study was designed to determine the prevalence of developmental and acquired dental anomalies in Iran.

\section{MATERIALS AND METHODS}

In this descriptive-analytical survey, 1,000 radiographs of patients referring to one $O$ ral and $M$ axillofacial Radiology Center in the city of Q azvin, I ran were randomly selected. Data were collected in 2011 to 2012. All the radiographs were taken by Soredex Cranex D digital panoramic system. The CD s containing panoramic radiographs were detached from the files and coded with numbers, then presented to two observers. The observers were intern students of dentistry who were trained for this reason. They were blinded to each other. The observers evaluated the radiographs and registered the data in separate forms. The cases which were considered having anomaly were reevaluated by oral and maxillofacial radiologist who had at least 8 years history of working.

The data were analyzed using SPSS software. Chi-square and Fisher exact tests were used for analysis. A significance level of 0.05 was used.

\section{RESULTS}

The total number of 1,000 panoramic radiographs of the patients referring to oral and maxillofacial radiology from dental anomaly aspect was evaluated [424 (42.4\%) male and $576(57.6 \%)$ female]. These anomalies were included: Supernumerary teeth, missing teeth, anomalies related to tooth size, anomalies related to tooth eruption, developmental anomalies and acquired anomalies.

Comparative prevalence of dental anomalies considering sex is shown in Tables 1 to 7 . Using Fisher exact test significance level for Table 1 is 0.429 which means there is no significant difference between sex and supernumerary teeth. It seems that preval ence of supernumerary teeth in male $(0.94 \%)$ is more than female $(0.69 \%)$. Using Chi-square test, the p-value for Table 2 is 0.067 which means that there is no significant difference between sex and missing teeth. The most prevalence tooth missing in male was mandibular premolar $2.6 \%$. In female it was maxillary premolar and maxillary lateral incisor $(2.7 \%)$. Totally the prevalence of missing teeth in male (8.7\%) was more than females (7.3\%).

U sing Fisher exact test, the p-value for T able 3 is 0.719 which means there is no significant difference between sex 


\begin{tabular}{|c|c|c|c|c|c|c|}
\hline \multirow[b]{2}{*}{ Supernumerary tooth } & \multicolumn{2}{|c|}{ Male } & \multicolumn{2}{|c|}{ Female } & \multicolumn{2}{|c|}{ Total } \\
\hline & $n$ & $\%$ & $n$ & $\%$ & $\mathrm{n}$ & $\%$ \\
\hline Distodens & 2 & 0.47 & 4 & 0.69 & 6 & 0.6 \\
\hline Mesiodens & 2 & 0.47 & 0 & 0 & 2 & 0.2 \\
\hline \multirow[t]{2}{*}{ Total } & 4 & 0.94 & 4 & 0.69 & 8 & 0.8 \\
\hline & \multicolumn{6}{|c|}{$p=0.429$} \\
\hline
\end{tabular}

\begin{tabular}{|c|c|c|c|c|c|c|}
\hline \multirow[b]{2}{*}{ Missing tooth } & \multicolumn{2}{|c|}{ Male } & \multicolumn{2}{|c|}{ Female } & \multicolumn{2}{|c|}{ Total } \\
\hline & $n$ & $\%$ & $n$ & $\%$ & $\mathrm{n}$ & $\%$ \\
\hline Maxillary premolar & 13 & 3 & 16 & 2.7 & 29 & 2.9 \\
\hline Mandibular premolar & 11 & 2.6 & 5 & 0.9 & 16 & 1.6 \\
\hline Canine & 7 & 1.6 & 5 & 0.9 & 12 & 1.2 \\
\hline Lateral incisor & 6 & 1.4 & 16 & 2.7 & 22 & 2.2 \\
\hline \multirow[t]{2}{*}{ Total } & 37 & 8.7 & 42 & 7.3 & 79 & 7.9 \\
\hline & \multicolumn{6}{|c|}{$p=0.067$} \\
\hline
\end{tabular}

\begin{tabular}{|c|c|c|c|c|c|c|}
\hline \multirow{2}{*}{ Tooth size } & \multicolumn{2}{|c|}{ Male } & \multicolumn{2}{|c|}{ Female } & \multicolumn{2}{|c|}{ Total } \\
\hline & $n$ & $\%$ & $n$ & $\%$ & $\mathrm{n}$ & $\%$ \\
\hline Macrodontia & 4 & 0.94 & 6 & 1 & 10 & 1 \\
\hline Microdontia & 17 & 4 & 15 & 2.6 & 32 & 3.2 \\
\hline \multirow[t]{2}{*}{ Total } & 21 & 4.9 & 21 & 3.6 & 42 & 4.2 \\
\hline & \multicolumn{6}{|c|}{$p=0.719$} \\
\hline
\end{tabular}

and tooth size-related anomalies. According to this table the prevalence of microdontia is more than macrodontia in both male and female.

A mong the anomalies related to the tooth eruption only two cases of fusion was observed in females and the prevalence of other eruption-related anomalies were not observed (for Table $4 \mathrm{p}$-value cannot be calculated).

Using Chi-square test, the p-value for Table 5 is 0.336 which means there is no significant difference between sex and other developmental anomalies. The most prevalent anomaly was dilacerations in male $2.8 \%$.

Using Fisher exact test, the $p$-value for Table 6 is 0.2 which means there is no significant difference between sex and acquired anomalies. The most prevalent anomaly was internal resorption (1\%). Totally the prevalence of acquired anomalies in man $1.6 \%$ was more than female $0.52 \%$.

Using Chi-square test, the p-value for Table 7 is 0.795 which means that there is no significant difference between sex and tooth impaction. The most prevalent anomaly was third molar impaction in female $(41.4 \%)$ followed by third molar impaction in male (36\%).

\section{DISCUSSION}

The data of the present study were collected from Iranians who attended in one oral and maxillofacial center.
Distribution the results of this study to vast population must be taken with caution. However, this data may be helpful to understand the general pattern of these anomalies and may impact on dental treatment provided in the community. In this study, we evaluate the prevalence rate of most commonly occurring dental abnormalities. Prevalence of these abnormalities is very low compared with dental caries and periodontal diseases, but they are more challenging for clinicians

Tooth impaction accounted for the highest prevalence at $41.7 \%$. This figure was generally higher than those from other population groups. A fify reported ${ }^{5}$ a prevalence of $21.2 \%$ among W estern Saudi A rabia. A nastasia reported ${ }^{6}$ a prevalence of $13.7 \%$ in Greece. Ghapanchi reported prevalence $4.34 \%$ in Shiraz, Iran. Ezoddini reported ${ }^{2}$ a prevalence of $8.3 \%$ in $Y$ azd, Iran.

Tooth missing accounted for $7.9 \%$ prevalence in this study. In other population groups the prevalence amount showed different figures. A fify reported ${ }^{5}$ a prevalence of $25.7 \%$ which was 2.5 times more than our study. G hapanchi reported ${ }^{2}$ a prevalence of $4.25 \%$ in Shiraz, Iran which was lower than our study. K ing reported ${ }^{7}$ a prevalence of $7.3 \%$ which was a bit lower than our study. M icrodontia accounted for $3.2 \%$ prevalence in the present research. Ghapanchi's results $^{2}$ were different from those of ours $(5.06 \%)$. 


\begin{tabular}{|c|c|c|c|c|c|c|c|}
\hline \multirow{2}{*}{ Tooth eruption } & \multirow{2}{*}{ Gender } & \multicolumn{2}{|c|}{ Male } & \multicolumn{2}{|c|}{ Female } & \multicolumn{2}{|c|}{ Total } \\
\hline & & $\mathrm{n}$ & $\%$ & $\mathrm{n}$ & $\%$ & $\mathrm{n}$ & $\%$ \\
\hline Fusion & & 0 & 0 & 2 & 0.34 & 2 & 0.2 \\
\hline Transposition & & 0 & 0 & 0 & 0 & 0 & 0 \\
\hline Concrescence & & 0 & 0 & 0 & 0 & 0 & 0 \\
\hline Total & & 0 & 0 & 2 & 0.34 & 2 & 0.2 \\
\hline
\end{tabular}

\begin{tabular}{|c|c|c|c|c|c|c|}
\hline \multirow[b]{2}{*}{ Developmental anomaly } & \multicolumn{2}{|c|}{ Male } & \multicolumn{2}{|c|}{ Female } & \multicolumn{2}{|c|}{ Total } \\
\hline & $\mathrm{n}$ & $\%$ & $\mathrm{n}$ & $\%$ & $\mathrm{n}$ & $\%$ \\
\hline Taurodontism & 0 & 0 & 2 & 0.34 & 2 & 0.2 \\
\hline Dilaceration & 12 & 2.8 & 10 & 1.7 & 22 & 2.2 \\
\hline Odontoma & 2 & 0.47 & 2 & 0.34 & 4 & 0.4 \\
\hline Germination & 0 & 0 & 0 & 0 & 0 & 0 \\
\hline \multirow[t]{2}{*}{ Total } & 14 & 3.27 & 14 & 2.38 & 28 & 2.8 \\
\hline & \multicolumn{6}{|c|}{$p=0.336$} \\
\hline
\end{tabular}

\begin{tabular}{|c|c|c|c|c|c|c|}
\hline \multirow[b]{2}{*}{ Acquired anomaly } & \multicolumn{2}{|c|}{ Male } & \multicolumn{2}{|c|}{ Female } & \multicolumn{2}{|c|}{ Total } \\
\hline & $\mathrm{n}$ & $\%$ & $n$ & $\%$ & $n$ & $\%$ \\
\hline Internal resorption & 4 & 0.94 & 0 & 0 & 4 & 0.4 \\
\hline External resorption & 0 & 0 & 0 & 0 & 0 & 0 \\
\hline Hypercementosis & 3 & 0.7 & 3 & 0.52 & 6 & 0.6 \\
\hline \multirow[t]{2}{*}{ Total } & 7 & 1.6 & 3 & 0.52 & 10 & 1 \\
\hline & \multicolumn{6}{|c|}{$p=0.2$} \\
\hline
\end{tabular}

\begin{tabular}{|c|c|c|c|c|c|c|}
\hline \multirow[b]{2}{*}{ Tooth impaction } & \multicolumn{2}{|c|}{ Male } & \multicolumn{2}{|c|}{ Female } & \multicolumn{2}{|c|}{ Total } \\
\hline & $n$ & $\%$ & $n$ & $\%$ & $n$ & $\%$ \\
\hline Wisdom & 153 & 36 & 239 & 41.4 & 392 & 39.2 \\
\hline Canine & 9 & 2.1 & 12 & 2 & 21 & 2.1 \\
\hline Lateral incisor & 0 & 0 & 3 & 0.52 & 3 & 0.3 \\
\hline 2nd mandibular molar & 1 & 0.23 & 0 & 0 & 1 & 0.1 \\
\hline \multirow[t]{2}{*}{ Total } & $16 \overline{3}$ & 38.4 & 254 & 43.9 & 417 & 41.7 \\
\hline & \multicolumn{6}{|c|}{$p=0.795$} \\
\hline
\end{tabular}

Ezoddini's research ${ }^{8}$ resulted in a prevalence of 3.5\% in the city of $Y$ azd, Iran. Guttal reported ${ }^{9}$ a prevalence of $9.14 \%$ in the population of India which was higher than our study.

Dilacerations accounted for $2.2 \%$ prevalence in the present research. A fify reported ${ }^{5}$ a prevalence of 1.15 for such in anomaly in Saudi A rabia. Our figure is lower than that reported by Ezoddini (15\%) in Y azd, Iran. ${ }^{8}$ Figure of $1.44 \%$ was reported by $\mathrm{G}$ hapanchi ${ }^{2}$ which was a bit higher than our study.

M acrodontia accounted for $1 \%$ prevalence in the present research. Guttal reported ${ }^{9}$ a prevalence of $0.28 \%$ in India. Ezoddini found ${ }^{8}$ that this anomaly accounted for $0.2 \%$ of prevalence among $\mathrm{Y}$ azd (Iran) patients and $\mathrm{A}$ tac reported ${ }^{10}$ the prevalence of $0.3 \%$ for this anomaly in Turkey.
Supernumerary teeth accounted for $0.8 \%$ prevalence in this study. It was lower than the figure of $2.4 \%$ reported by Ezoddini in $Y$ azd, $\operatorname{Iran}^{8}$ and higher than A fify's results ${ }^{5}$ $(0.3 \%)$ in Saudi A rabia. Guttal found ${ }^{9}$ that this anomaly accounted for $0.4 \%$ of all dental anomalies among Indian population.

A total of 1,751 Iranian orthodontic patients were examined by $V$ ahid-D astjerdi et al $(2011)^{11}$ and they found that $0.74 \%$ had supernumerary teeth. These investigators also reported ${ }^{12}$ that nonsyndromic hypodontia in Iranian orthodontic patients were 197 congenitally missing teeth in 160 patients $(9.1 \% ; 74$ boys and 86 girls).

Taurodontism was defined as the presence of an apically displaced pulp chamber without the usual constriction of cement enamel junction. In this study this anomaly 
Frequency and Distribution of Dental Anomalies in Iran: A Radiographic Survey

accounted for $0.2 \%$ of the prevalence. Afify reported ${ }^{5}$ a prevalence of $0.1 \%$ taurodontism in A rabian dental patients. A Iso Guttal reported ${ }^{13}$ a prevalence of $0.3 \%$ of this anomaly among Indian patients. Ghapanchi in Shiraz, ${ }^{2}$ Iran found that taurodontism is more prevalent in patients $(0.96 \%)$. Ezoddini's research reported ${ }^{8}$ a prevalence of $7.5 \%$ of taurodontism in Y azd, I ran which was about 39 times higher than our study. Our results show that taurodontism is uncommon in Qazvin but further studies are required to assess its prevalence in the general population.

Fusion accounted for $0.2 \%$ prevalence in this study which was equal to Ezoddini's research ${ }^{8}$ in $Y$ azd, Iran. Guttal reported ${ }^{9}$ lower prevalence of $0.8 \%$ for Indian population. A tac reported ${ }^{10}$ a prevalence of $0.23 \%$ for such anomaly in Turkey.

Germination, transposition and concrescence were not found in our study. Guttal reported ${ }^{9}$ a prevalence of 0.28 and $0.02 \%$ for germination and concrescence respectively. In the Indian population in the study of king in $\mathrm{China}^{7}$ the prevalence of germination was al so higher than ours $(0.8 \%)$. A tac also reported ${ }^{10}$ a higher prevalence for germination in Turkey $(0.07 \%)$.

A mong the acquired dental anomalies, hypercementosis accounted for the highest prevalence at $0.6 \%$ which was lower than K ositbowornchai's study in Thai $(1.2 \%){ }^{13}$

The prevalence of internal and external resorption was $0.4 \%$ and 0 respectively. No study was found to compare our results with.

A ccording to investigations mentioned previously, abnormal variations occur in many cases are due to genetic, environmental and pathological factors and should be followed. Recognizing these anomalies will facilitate the dental treatment of patients with these anomalies.

\section{CONCLUSION}

The data from this survey and comparison with other studies showed that dental anomalies occur with different frequencies around the world. These anomalies are under genetic and environmental control, therefore contribute to regional differences. Although each of these anomalies has low prevalence in the dental clinics, their presence may create a management problem and complicate the treatment. Therefore, their diagnosis and management are important for general practitioner.

\section{ACKNOWLEDGEMENT}

This article was based on an undergraduate thesis by Dr Neirizi, which was successfully completed under supervision of Dr A zimi with the close cooperation of the Oral and M axillofacial Radiology Department of the Dental School of Qazvin University of M edical Sciences and Oral
Medicine Department of the Dental School of Shahid B eheshti, U niversity of M edical Sciences.

\section{REFERENCES}

1. White SC, Pharoah MJ. Oral radiology, principles and interpretation (6th ed). St. Louis: M osby 2009:295.

2. Ghapanchi J, Haghnegahdar AA, K hodadazadeh SH, Haghnegahdar S. A radiographic and clinical survey of dental anomalies in patients referring to Shiraz Dental School. Shiraz Univ Dent J 2010;10:26-31.

3. Rstavik D, Pitford TR. Essential endodontology. Chapter 6. Blackwell Science 1998:131-56.

4. White SC. O ral radiology principles and interpretation (6th ed). Chapter 5. St. Louis: M osby; 2009:117-45.

5. A fifyy $A R$, Zawawi $\mathrm{KH}$. The prevalence of dental anomalies in the Western region of Saudi A rabia. ISRN Dent 2012 J un;2012(2012):1-5.

6. Anastasia F, A thena K, Zaki B, Nikolaos P, A nastasios T. Incidence of impacted and supernumerary teeth-a radiographic study in a North Greek population. Med Oral Patol Oral Cir Bucal 2011 Jan;16(1):56-61.

7. K ing NM, Tsai JSJ, Wong HM . M orphological and numerical characteristics of the Southern Chinese dentitions. Part I: A nomalies in the permanent dentition. Open A nthropol J 2010;3:54-64.

8. Ezoddini AF, Sheikhha M H, A hmadi H. Prevalence of dental developmental anomalies: A radiographic study. Community Dent Health 2007;24(3):140-44.

9. Guttal KS, Naikmasur V G, B hargava P, B athi RJ. Frequency of developmental dental anomalies in the Indian population. Eur J Dent 2010 Jul;4(3):263-69.

10. Altug-A taca AT, Erdem D. Prevalence and distribution of dental anomalies in orthodontic patients. A m J Orthod Dentofacial Orthop 2007;131(5):510-14.

11. V ahid-Dastjerdi E, B orzabadi-Farahani A, M ahdian M, A mini $\mathrm{N}$. N on-syndromic hypodontia in an Iranian orthodontic population. J Oral Sci 2010;52:455-61.

12. V ahid-Dastjerdi $E, B$ orzabadi-Farahani $A, M$ ahdian $M, A$ mini $N$. Supernumerary teeth amongst I ranian orthodontic patients. A retrospective radiographic and clinical survey. A cta O dontol Scand 2011;69:125-28.

13. Kositbow ornchai $\mathrm{S}, \mathrm{K}$ einprasit $\mathrm{CH}$, Poomat N. Prevalence and distribution of dental anomalies in pretreatment orthodontic Thai patients. KDJ 2010 Jul-Dec;13(2):92-100.

\section{ABOUT THE AUTHORS}

\section{Maryam Tofangchiha}

A ssistant Professor, Department of O ral and M axillofacial Radiology Qazvin U niversity of M edical Sciences, Q azvin, Iran

\section{Somayyeh Azimi (Corresponding Author)}

Assistant Professor, Department of Oral M edicine, Shahid B eheshti University of M edical Sciences, Tehran, Iran, Phone: +982144221233 e-mail: somayyeh_azimi@yahoo.com

\section{Masoud Neirizi}

Dentist (General Practitioner), Department of Oral M edicine, Iran 